\title{
Profissionais e profissionalização em Tecnologia da Informação: indicativos de controvérsias e conflitos
}

\author{
IT professionals and professionalization: controversial and conflictual occurrences in \\ the field
}

Pedro Jácome de Moura Junior ${ }^{1}$

Diogo Henrique Helal ${ }^{2}$

\begin{abstract}
Resumo
As tecnologias da informação e comunicação (TICs) são consideradas ubíquas e pervasivas em relação à vida humana. À luz dos modelos teóricos de profissionalização de Abbott (1988) e Freidson (1984), discute-se o processo de profissionalização em tecnologia da informação ( $\mathrm{TI}$ ) e o papel desempenhado pelos profissionais da área nesse processo. A literatura sobre sociologia das profissões e sobre profissionalização em TI é consultada em busca de resposta às questões: quem são os profissionais de TI? Como se dá a sua formação? Quais são os instrumentos de regulamentação da sua atuação? Controvérsias e conflitos são identificados e discutidos, com ênfase no ideário do "software livre"; na determinação da indústria sobre a ação profissional; nas relações de poder; na autorregulação da profissão; na participação dos profissionais de TI em novas profissões; em aspectos de personalidade, visão de mundo e cultura; no licenciamento para exercício profissional; no domínio do conhecimento e em aspectos de litígio. Proposições de pesquisa são oferecidas como contribuição ao aprofundamento de cada uma das controvérsias e conflitos discutidos.
\end{abstract}

Palavras-chave: Tecnologia da Informação e Comunicação. Profissionais de TI. Profissionalização.

\begin{abstract}
Information and communication technologies (ICT) are considered ubiquitous and pervasive in human life. In light of Abbott (1988) and Freidson's (1984) theoretical models of professionalization, this essay discusses the process of professionalization in information technology (IT) and the role of IT professionals in this process. The literature on the sociology of professions and professionalization in IT is consulted, looking for answers to the questions: Who are the IT professionals? How are they trained/What do they study? What are the regulatory instruments of their performance? Controversial and conflictual occurrences in the field are identified and discussed, with emphasis on the ideology of "open source" software; on the industry's determination over professional action; on power relations; on profession's selfregulation; on the participation of IT professionals in new professions; on personality, worldview and cultural aspects; on licensing for professional practice; on domain of knowledge and on litigation aspects. Research propositions are offered as a contribution to the deepening of each of the controversies and conflicts discussed.
\end{abstract}

Keywords: Information and communication technology (ICT). IT professionals. Professionalization.

Artigo submetido em 02 de agosto de 2013 e aceito em 12 de fevereiro de 2014.

DOI: http://dx.doi.org/10.1590/1679-39519889

1 Analista de sistemas; especialista, mestre e doutorando em Administração pela Universidade Federal da Paraíba (UFPB). Endereço: UFPB, Campus I, STI, CEP 58051-900, João Pessoa-PB, Brasil. E-mail: pjacome@sti.ufpb.br

Professor Adjunto do Programa de Pós Graduação em Administração (PPGA) da Universidade Federal da Paraíba (UFPB); Doutor em Ciências Humanas, concentração em Sociologia pela Faculdade de Filosofia e Ciências Humanas da Universidade Federal de Minas Gerais (UFMG). Endereço: UFPB/CCSA, Campus I, CEP 58051-900, João Pessoa-PB, Brasil. E-mail: diogohh@yahoo.com.br 


\section{Introdução}

As tecnologias da informação e comunicação (TICs) são consideradas ubíquas e pervasivas (LEUNG, 2011) em relação à vida humana. Seja no trabalho, no lazer, em casa ou em viagem, seja por obrigação contratual ou por hedonismo, é possível afirmar que as TICs estão presentes nas atividades humanas, mesmo que essa presença seja imperceptível.

Nos veículos automotores (automóveis, aviões, barcos e trens), por exemplo, boa parte das funções de controle - como aceleração e frenagem - é realizada por meio de computadores. Na área da saúde, TICs são aplicadas, direta ou indiretamente, na manutenção de vidas humanas. Em todos os setores produtivos (primário, secundário e terciário), os processos de negócio são suportados por sistemas de informação (SI), em suas formas mais simples, como bancos de dados implementados por meio de planilhas eletrônicas, e sofisticadas, como sistemas integrados de gestão (ERP) e de inteligência empresarial (BI).

Se essa ubiquidade e pervasividade das TICs de fato ocorre, as taken for granted, é dedutível que haja, hoje, uma forte relação entre a sociedade e os profissionais que desenvolvem essas tecnologias. Mas quem são esses profissionais? Como se dá a sua formação? Quais são os instrumentos de regulamentação da sua atuação?

À luz dos modelos teóricos de profissionalização de Abbott (1988) e Freidson (1984), discutem-se o processo, em curso, de profissionalização em TI e o papel desempenhado pelos profissionais da área nesse processo. A relevância do tema evidencia-se na dependência da sociedade, hoje, do adequado funcionamento das tecnologias da informação e, por conseguinte, dos profissionais de TI.

Para consecução dos objetivos propostos, invocar-se-á a literatura precedente e advinda da sociologia sobre as profissões, com o intuito de apresentação dos fundamentos do tema. Em seguida, apresentar-se-ão definições conceituais correntes para o termo "profissional de TI" e justificar-se-á a opção por definição própria para o desenvolvimento deste trabalho. Em sequência, apresentar-se-ão discussões correntes sobre a profissionalização específica em TI, com o intuito de ilustração de temas que têm merecido a atenção dos pesquisadores na área. Depois, apresentar-se-ão discussões correntes sobre o papel que tem sido desempenhado pelos profissionais de TI no processo de profissionalização, com o intuito de ilustrar sua visão do processo com base em seus comportamentos perceptíveis. Por fim, uma vez percebido de que forma as discussões específicas em TI se relacionam com a discussão geral em sociologia das profissões, apresentar-se-ão insights, posicionamentos e questionamentos decorrentes desse relacionamento.

\section{Profissões e Profissionalização sob o Enfoque Sociológico}

A sociologia das profissões, que surgiu como uma abordagem sociológica das ocupações modernas, hoje se consolida como um campo autônomo, com autores e teorias próprias, bem como objetos de pesquisa e metodologias (SANTOS, 2001). Cumpre destacar, inicialmente, as bases funcionalistas no desenvolvimento da sociologia das profissões, em particular nos Estados Unidos.

Foram os funcionalistas os primeiros a debaterem o papel das profissões nas sociedades modernas. "De maneira geral, eles deram ênfase à formação profissional e à constituição dos papéis profissionais como decorrência da modernização inexorável das sociedades, valorizando os profissionais na estrutura social" (SANTOS, 2001, p. 26).

Nessa perspectiva, partindo-se do questionamento sobre "o que é uma profissão", há que se preocupar em definir o conceito, o que passa pelo estabelecimento daquilo que é intrínseco e do que é distintivo, de forma a assegurar ao conceito um escopo ao mesmo tempo convergente e discriminante. Para Rodrigues (2002) seria a definição do "tipo ideal" de profissão, como mencionado em Rodriguez e Guillen (1992, p. 7), um modelo funcional, organizado e mensurável, que serviria de referência para classificação de grupos de ocupação. 
Na perspectiva funcionalista, Parsons (1968), buscando compreender o aumento da influência das profissões na estratificação social nas sociedades modernas, concluiu que o aumento da importância dos grupos profissionais deriva de seu sucesso em transformar os elementos mais valorizados do sistema cultural moderno (competência técnica e racionalidade científica) em base para a legitimação do status e da autoridade profissionais.

Segundo essa abordagem, atribuída a Carr-Saunders e Wilson (1934) e outros, o que motivaria a constituição de profissões seria: (a) a satisfação da clientela, pela capacidade de oferecimento de serviços especializados; (b) a demanda por códigos de conduta e ética, que garantam exclusividade do exercício; e (c) o desenvolvimento de uma cultura profissional, possível por meio de formação específica.

Freidson (1984) também realizou importantes desenvolvimentos na análise dos grupos profissionais, mas em uma perspectiva distinta: interacionista. Em seus estudos, buscou compreender como o conhecimento profissional, identificado como um conhecimento formal, haja vista seu vínculo ao sistema de ensino superior, pode ser transformado em um recurso para a aquisição de poder. "O ponto de partida é a análise do processo de institucionalização do conhecimento que [...] foi capaz de criar divisões internas nos grupos profissionais, das quais emergiram subgrupos profissionais que se diferenciam quanto ao grau e tipo de poder" (VENUTO, 1999, p. 3).

Com base nos conceitos de técnica e disciplina, de Foucault, e de prestígio e respeito, de Haug (1973), Freidson (1984) fornece quatro características-chave que ajudariam a distinguir uma profissão: controle legítimo (autonomia) sobre o trabalho, grau de estima e confiança do público, conhecimento abstrato (lacunas de habilidades e competências entre os profissionais e o público) e monopólio sobre a execução da atividade.

Adicionalmente, Haug (1973) argumenta que as profissões seriam orientadas também por razões altruístas, e não econômicas, e que seria a "reciprocidade assimétrica", com base na díade conhecimento/ignorância, que favoreceria a institucionalização3 das profissões e o acúmulo de prestígio e respeito por parte dos profissionais. Do "[...] equilíbrio entre motivações e necessidades do profissional e do cliente", nasceria um processo de legitimação ${ }^{4}$ que apoiaria a "definição de um corpo de saberes, testado e controlado pelos profissionais e reconhecido pelo Estado". Essa dinâmica de legitimação seria suficiente para sobrepujar as discussões subjacentes sobre poder, monopólio e privilégios profissionais (BRINT, 1992; RODRIGUES, 2002, p. 10).

Outro autor interacionista, Hughes (1958), por sua vez, toma como ponto de partida, para explicar as profissões, a divisão social do trabalho (com base nas atividades), levando em conta os conceitos de licença e mandato. Licença seria a autorização legal para exercício exclusivo de determinada atividade, enquanto mandato seria o compromisso de oferecer um serviço especializado. Por isso, seria mais importante, segundo Hughes (1958), identificar contextos e eventos que levam uma ocupação a se transformar em profissão - ou seja, o processo de profissionalização - do que descrever, propriamente, o que seria uma profissão.

A noção de profissionalização, afeita aos interacionistas, possibilita a análise da socialização do profissional, não restrita à formação profissional, como nos funcionalistas, e por consequência, da própria atuação profissional no mercado de trabalho. Afirma o próprio Freidson (1986, p. 34): “[...] profissão pode ser mais que uma ocupação à qual se juntou prestígio devido ao seu corpo de conhecimento formal. Ela pode ser também uma ocupação de trabalho beneficiária de 'fechamento social' de sinecuras de abrigos no mercado de trabalho".

${ }^{3}$ Conceito baseado em Meyer, Boli, Thomas et al. (1994, p. 10), que define um padrão de atividades mantido de modo normativo e cognitivo, e praticamente assumido como legítimo (seja a partir de uma lei formal, costume ou conhecimento).

${ }^{4}$ Condição que reflete alinhamento cultural, apoio normativo e consonância com leis e regras relevantes (SCOTT, 1995). 
O principal ponto de divergência entre a profissionalização e a abordagem utilitarista, ${ }^{5}$ seria a ênfase na diversidade e no conflito, pois as profissões não seriam unidades homogêneas de identidade, valores e interesses. Ao contrário, seriam espaços de disputa entre segmentos e, portanto, em constante mutação, avanço (no sentido de mudança), redefinições e estabelecimento de novos relacionamentos, interna e externamente (RODRIGUES, 2002). O processo histórico de construção de uma profissão seria, então, segundo Wilensky (1964, p. 21), uma "[...] sequência de eventos ou etapas seguidas pelos grupos ocupacionais até [o alcance] do estágio do profissionalismo". As etapas seriam: passagem de atividade amadora a ocupação em tempo integral; estabelecimento de controle sobre a formação; criação de associação profissional; proteção legal; e definição de código de ética.

Abbott (1988) viria a criticar essa conceituação, apontando que as profissões evoluiriam em muitas direções e em ritmos diferentes e, além disso, sofreriam influências da cultura e da(s) sociedade(s) na(s) qual(is) está(ão) imersa(s) e, em razão disso, não faria sentido pensar em profissionalização em termos de um continuum. O tema central do desenvolvimento das profissões deveria ser a análise das relações interprofissionais e do conteúdo da atividade profissional (BUREAU e SUQUET, 2009). Para Abbott (1988), a ação profissional precederia a profissionalização, e a chave para o entendimento de como se inicia o processo de profissionalização seria a identificação do problema que, reinvindicando a si, um grupo de profissionais se propõe a resolver.

O grau de abstração do conhecimento é o que dá poder a uma profissão (ABBOTT, 1988). Em seu conceito de jurisdição, Abbott refere-se ao direito à exclusividade da prática profissional por um determinado grupo profissional. O domínio de uma jurisdição relaciona-se, segundo o autor, ao controle cultural e social. O primeiro é exercido no desempenho da atividade profissional, é legitimado pelo conjunto de conhecimento acadêmico e é aceito pela sociedade. O segundo, por sua vez, é obtido por meio de reivindicações da profissão via mercado de trabalho, meios legais e opinião pública.

Cumpre destacar que Abbott, além de considerar o conhecimento como base de legitimação da autoridade profissional, avança, em comparação a Parsons, ao considerar que a emergência e consolidação da autoridade profissional passam pela análise da competição interprofissional, processo em que diversos grupos lutam pelo controle de uma jurisdição profissional. Para Venuto (1999), ao examinar o fenômeno da competição interprofissional e desenvolver o conceito de jurisdições profissionais, Abbott dá um salto em relação à análise parsoniana, ao considerar o controle jurisdicional um processo social de disputa entre agentes pela construção e legitimação do controle sobre o conhecimento e o saber que a profissão reivindica como seus.

Percebe-se claramente que em Freidson e em Abbott, ao se tratar de profissões, o conhecimento é o principal instrumento estruturador dos grupos ocupacionais. Independente do modo como é apresentado competência técnica funcional, grau de abstração ou potencial de formalização -, "[...] o fato é que o conteúdo do saber profissional e sua base de fundamentação racional-científica explicam o sucesso dos vários grupos ocupacionais na luta por sua consolidação enquanto subcampo profissional" (VENUTO, 1999, p. 3).

A noção de profissionalização e a importância do conhecimento em ambos autores - Freidson e Abbott serão retomadas mais adiante, ao longo da discussão sobre as profissões em TI.

${ }^{5} \mathrm{O}$ mesmo que funcionalista, no caso. 


\section{O Profissional de TI - Definições e Caracterização}

O termo "Tecnologia da Informação" foi introduzido na literatura organizacional para enfatizar a convergência entre as áreas de computação e telecomunicações, e surgiu em meio a termos em uso como "ciência da computação", "estudos em computação", "sistemas de informação", "processamento da informação", "informática", "análise de sistemas" e "processamento de dados" (SHAPIRO, 1994). Para os fins deste ensaio, adotar-se-á TI como nomenclatura que abarca diversos termos na área, inclusive TIC ou TICs.

Por outro lado, a caracterização, em si, do que vem a ser "profissional de TI" é dificultada pela diversidade de definições encontradas na literatura (FREEMAN e ASPRAY, 1999). Ora este profissional é definido funcionalmente como aquele que apoia outra pessoa no uso de computadores, seja ao desenvolver produtos e serviços em empresas específicas de TI, ou ao fazê-lo em equipes em outras áreas de negócio (SEGRE e RAPKIEWICZ, 2003); ora é definido por meio de traços ou atributos profissionais, como o núcleo comum das ocupações em TI (BITTNER, 2004; FU, 2011); ora é definido pelo tipo de artefato de TI que manipula (NEVO, NEVO e EIN-DOR, 2009).

Uma forma alternativa de analisar esses profissionais seria por meio dos cargos (títulos dos cargos e atribuições) por eles ocupados. Em TI, os empregadores geralmente procuram por habilidades específicas, e não oferecem postos de trabalho com base em cargos e/ou definições genéricos (DONOHUE e POWER, 2012). Títulos de postos de trabalho em TI podem ter significados diferentes, dependendo do contexto, com descrições de cargos e responsabilidades que variam de uma organização para outra.

Os títulos de postos de trabalho em TI, bem como seus papéis e significados, surgem a partir de 1930, quando da emergência dos computadores (DONOHUE e POWER, 2012). Entre os anos 50 e início dos anos 90, os papéis em TI começaram a se desenvolver e, durante esse período, permaneceram relativamente bem definidos. Barnes e Gotterer (1975) relatam a existência, à época, de 11 títulos de postos de trabalho em TI, que hoje poderiam ser bem traduzidos em cinco categorias: analistas de sistemas, analistas de suporte, programadores, operadores de computador e funções específicas por área (vendas, instrução etc.).

A posterior diversidade de métodos e técnicas, atrelada à demanda dos empregadores por aplicações com fins de ganhos em competitividade, teriam implicado mudanças nas qualificações profissionais, resultando em cargos com definições "obscuras" para trabalhos muito específicos (DONOHUE e POWER, 2012, p. 6). A modalidade de desenvolvimento em código aberto (open source) teria adicionado novos requisitos às habilidades dos desenvolvedores (como metodologias específicas para trabalho realizado por grupos espacialmente dispersos) e limitado os recursos de responsabilização (DONOHUE e POWER, 2012), recursos esses considerados fatores indispensáveis na profissionalização das engenharias como um todo (COLLINS, GHEY e MILLS, 1989).

Ou seja, aparentemente, por meio dos postos de trabalho, títulos de cargos e atribuições, haveria alguma possibilidade de caracterização do profissional de TI. Não obstante, a dinâmica inerente à organização do trabalho na área atuaria no sentido de tornar rapidamente obsoletas as definições profissionais, ou mesmo as especialidades dentro da profissão. Não seria, portanto, o caso de não se poder caracterizar o profissional e a sua profissão. Seria o caso de se aplicar prazo de validade a essas caracterizações.

Para os fins deste ensaio, o "Profissional de TI" é definido, portanto, como o indivíduo que atua na área de TI com atividade remunerada, em postos relacionados ao design (análise de sistemas, suporte técnico, suporte operacional, programação de computadores, implantação de sistemas, testes de sistemas, levantamento de requisitos), gerência (de projetos, de equipes, de recursos) e usuários (usuário-chave, equipe-cliente). A opção por essas três categorias profissionais deve-se à sua atuação fortemente interrelacionada (BUREAU e SUQUET, 2009; NEVO, NEVO e EIN-DOR, 2009) na área de TI e a escolha pela definição por postos - em vez de abordagem funcionalista ou baseada em traços -, à possibilidade de 
mapeamento de novos e emergentes postos em macrocategorias mais estáveis, como design, gestão e uso, aqui propostas.

\section{Profissionalização das Ocupações em Tecnologia da Informação}

A despeito da relevância percebida por parte da sociedade quanto aos papéis social e econômico de atuação do profissional de TI (ABBOTT, 1988; FURTMUELLER, WILDEROM e RAO, 2011; ORLIKOWSKI e BAROUDI, 1988), a profissionalização das ocupações atuantes em TI é tema controverso - seja do ponto de vista acadêmico (dos modelos empregados nos estudos), do ponto de vista gerencial (dos títulos de cargos, da carreira ou das atribuições), do ponto de vista de outros profissionais (sobre a profissão em TI) ou ainda do ponto de vista dos próprios profissionais - e inspira investigação minuciosa, como se pretende realizar a seguir.

\section{A primeira controvérsia: profissão ou ocupação?}

De acordo com Freidson (1984), a diferença fundamental que distinguiria uma profissão de outras ocupações seria o controle legítimo (ou a autonomia) sobre o seu trabalho. Assim, o primeiro aspecto controverso seria manifestado pela questão: deve-se falar em profissão em TI ou em ocupação em TI? Analisando a emergência de profissão em outra área, Emmerich (2012) trata as profissões em TI como exemplos de pseudoprofissões por não serem socialmente institucionalizadas e legitimadas. Ilavarasan e Malish (2008) revelam que, ao menos nas condições de atuação na Índia (país reconhecido por sua significativa contribuição para a exportação global de software e serviços correlatos), as práticas profissionais em TI podem ser caracterizadas mais como uma ocupação do que como uma profissão.

Profissionais em TI são predominantemente descritos como profissionais ao terem o seu trabalho associado a uma profissão - nos meios acadêmicos, populares, e nas discussões políticas (ILAVARASAN e MALISH, 2008). No entanto, há uma preocupação crescente com relação a esses profissionais no sentido do reconhecimento do trabalho em TI como profissão e do estabelecimento de código de ética e de padrão de formação em muitos países.

Esforços têm sido empreendidos nessa direção, como os do IEEE (Institute of Electrical and Electronics Engineering), por meio da Computer Society, ou como os da ACM (Association for Computing Machinery) (DENNING, 2001). Apesar disso, a existência de códigos de ética distintos, elaborados por diferentes organizações, e a falta de sua aplicação ilustram o porquê de o trabalho em TI ainda não ter atingido o status de profissão (ILAVARASAN e MALISH, 2008). No Brasil, os esforços de regulamentação das profissões em TI ocorrem por meio de projeto de lei do Senado (PLS), protocolado sob o número 607, desde o ano de 2007, ainda sem votação definitiva. Curiosamente, este PLS enfrenta iniciativas contrárias, muitas originadas por profissionais em TI na forma de petições públicas variadas (PETIÇÃO PÚBLICA, n.d.).

Por meio do framework desenvolvido por Freidson (1984), Ilavarasan e Malish (2008) demonstram que apenas a dimensão "estima e confiança da sociedade" é atribuída aos profissionais de TI. As demais dimensões, ou seja, conhecimentos e habilidades necessários para realização do trabalho em TI não são, necessariamente, adquiridos por meio de treinamento credenciado formal, o que resulta em entrada aberta a todos, independentemente da sua educação e formação. Empregados em TI não têm controle sobre a definição de seu trabalho e de como executá-lo, nem sobre sua própria perícia técnica; e empregados em TI são constantemente avaliados por integrantes de outras ocupações. Ou seja, Ilavarasan e Malish (2008) retratam um profissional de TI, na Índia, que atende a apenas uma das dimensões propostas por Freidson (1984) para análise sobre se uma ocupação pode ser considerada profissão. 


\section{A segunda controvérsia: uma identidade linear ou multidimensional?}

Para Orlikowski e Baroudi (1988), as atuações em TI não corresponderiam à atuação de uma profissão, se se olhar para a TI tendo por base o framework de Freidson (1984), cuja perspectiva de profissionalização é linear. Corroborando essa opinião, Shapiro (1994) sugere que profissionalismo seria um processo difuso, diferente de um estado binário (é ou não é profissão). Além disso, Shapiro (1994) afirma também que públicos diferentes vão empregar conjuntos diferentes de critérios e ponderações, ao perceber se uma área de trabalho, incluindo seus praticantes, pode ser considerada como uma profissão. Essa característica multidimensional permitiria a introdução de questões - tais como as relativas à desqualificação (a possibilidade de um profissional ter o seu status no trabalho reduzido pela introdução de mudanças tecnológicas significativas) e a interesses pessoais (como gostar ou não gostar da tarefa, da equipe ou do líder) - associadas aos grupos profissionais, o que seria relevante para a análise do profissionalismo em TI (BITTNER, 2004; ORLIKOWSKI e BAROUDI, 1988).

Além disso, o problema da identidade profissional em TI permaneceria tendo talvez como principal causa a própria natureza da TI. Sendo uma área extremamente interdisciplinar, as sociedades de profissionais em TI abrangeriam uma gama quase ilimitada de potenciais membros, com uma variedade significativa de opiniões sobre o que é TI (SHAPIRO, 1994). Assim, determinar se a TI em geral é, ou deveria ser, considerada engenharia, arte, ciência ou qualquer outra coisa tem atraído a atenção de pesquisadores e práticos, uma vez que sentimentos de legitimidade e identidade - manifestados de acordo com a perspectiva da sociedade, de outros profissionais e dos próprios profissionais de TI - é que definiriam esse resultado (SHAPIRO, 1994).

Por meio de aplicação do framework proposto por Abbott, em estudo sobre profissionalização em TI, Bureau e Suquet (2009) sugerem que: (a) a mudança não é unidirecional; (b) a evolução de uma ocupação depende explicitamente da evolução de outras ocupações, pois há interdependências entre processos de profissionalização em curso; (c) a estrutura social e as reivindicações culturais das profíssões não são mais importantes do que a forma de atuação das profissões; (d) as profissões não são unidades homogêneas; e (e) profissionalização, como um processo, muda com o tempo.

Soma-se a isso a dificuldade de definições conceituais - e mesmo ontológicas - em TI, devido à aparente abstração e polivalência dos artefatos digitais (KALLINIKOS, AALTONEN e MARTON, 2013), à demanda por atualização constante quanto aos termos e variáveis empregados na produção prática e teórica em TI (MOTA, DE MOURA JR. e BELLINI, 2013); e ao constante debate sobre crise identitária no campo (BENBASAT e ZMUD, 2003).

Assim, enquanto alguns buscam "o" caminho da profissionalização em TI (DENNING, 2001; ILAVARASAN e MALISH, 2008), outros propõem múltiplos caminhos para ela (BITTNER, 2004; BUREAU e SUQUET, 2009; ORLIKOWSKI e BAROUDI, 1988).

\section{A terceira controvérsia: papel social e econômico ou meramente econômico?}

Price (2006), em texto publicado por The British Computer Society, sociedade de profissionais e acadêmicos de TI, responsável pela regulação da área no Reino Unido, aponta casos de autopromoção da profissão em TI na sociedade ao situar o profissional de TI no núcleo essencial da atividade produtiva. Observa-se, em exemplo como esse, que o valor do profissional de TI está geralmente associado à sua participação em procedimentos específicos, dedicados ao aumento da produtividade e da competitividade organizacional, o que é reiterado por outros autores (por exemplo, CASTELLS, 1999; FURTMUELLER, WILDEROM e RAI, 2011).

Desafiando essa posição, Bardini (2000) trata da gênese da computação pessoal distribuída e seu impacto na sociedade, especificamente o impacto da participação do indivíduo nas escolhas democráticas, tomando por 
base os ideais revolucionários franceses de liberdade, igualdade e fraternidade, associando-os a slogans criados pela área de TI: interfaces amigáveis (user-friendliness), acesso universal e interatividade respectivamente. Para Bardini (2000, p. 63), no entanto, essas seriam a "utopia da liberdade", "utopia da igualdade" e "utopia da fraternidade", como promessas que não passariam da "ideologia modernista", sempre determinada pela tecnologia e pelo mercado.

Existiria um discurso sergundo o qual as tecnologias digitais seriam concebidas como um meio a serviço do ideal revolucionário democrático (BARDINI, 2000). O progresso tecnológico seria o único caminho para o progresso social e as novas tecnologias de comunicação se tornariam o meio revolucionário, por excelência, para que a democracia representativa entrasse em uma nova fase, a e-democracia, ou o modelo político da sociedade da informação.

Um aspecto importante é a separação entre os designers de sistema (de informação) e os usuários desses sistemas, incluindo relação assimétrica de poder que seria estabelecida (BARDINI, 2000; MARKUS e BJORN-ANDERSEN, 1987; SEGRE e RAPKIEWICZ, 2003). Segre e Rapkiewicz (2003) caracterizam o início dessa atuação profissional como artesanal, quando um indivíduo (ou uma pequena equipe) tinha pleno domínio sobre o processo de trabalho e, para resolver um problema específico, propunha e implementava uma solução com base na aplicação de computadores. Nesse contexto inicial, o profissional e o usuário (direto) de TI eram os mesmos. Os especialistas que atuavam na área eram de diferentes comunidades profissionais (matemáticos, físicos, engenheiros etc.), treinados pelos próprios fabricantes de computadores. Portanto a separação entre designers e usuários teria sido um momento significativo no desenvolvimento da área de TI, já que, para fins de profissionalização, o conhecimento passaria a ser controlado por um grupo disposto a oferecer seus préstimos à sociedade.

No entanto, segundo Bardini (2000), esse seria justamente o ponto (no tempo) em que o usuário dos sistemas passaria a ser "modelado" pelos designers, uma vez que a representação desse (futuro) usuário, por parte dos designers, estaria relativamente espelhada em si (as interfaces gráficas de usuário demonstram a influência motora e cognitiva, por exemplo, dos designers sobre os usuários). De forma mais direta, Ben (2007, p. 318) destaca o papel de determinação do desenvolvedor sobre o trabalho dos usuários, pois que o desenvolvimento de software representaria "uma tarefa social, em que a realidade é re-gerada e projetada". Para Ben (2007), diferentes visões de mundo e experiências seriam "incorporadas em um produto e construídas como uma nova realidade" (BEN, 2007, p. 318).

Essa concepção (design reflexivo) levaria o usuário a representar o papel social de "trabalhador do conhecimento" numa sociedade da informação (BARDINI, 2000, p. 63).

\section{A quarta controvérsia: a influência de aspectos regulatórios mais que normativos}

Forças coercitivas, exercidas por agências reguladoras, influenciariam muito mais fortemente a mudança organizacional que forças normativas, exercidas por meio das influências da profissionalização e das redes profissionais (HU, HART e COOKE, 2006). No entanto, significativa parcela da literatura parece preferir investigar e discutir aspectos normativos da profissão. Laswell, Simmel e Behrens (1999), por exemplo, considerando a relevância da formação de profissionais especializados em segurança da informação, alertam para o fato de que não haveria, aparentemente, nenhum acordo sistemático sobre o conhecimento, as habilidades e competências necessárias para formulação de um currículo de profissionais de segurança da informação que conte com amplo apoio entre organizações (certificadoras e contratantes). Grajek (2011) trata da necessidade de normatização das profissões em TI por meio da educação formal. E Segre e Rapkiewicz (2003) enfatizam a necessidade de educação contínua na área. 
Em contraposição, trazendo à discussão aspectos do institucionalismo (DIMAGGIO e POWELL, 2007), Chen (2005) analisa o processo de profissionalização como isomórfico, ${ }^{6}$ já que na área de TI os profissionais, em geral, compartilham informações rapidamente e tendem a se identificar mais com suas especialidades (por exemplo, programadores ou analistas de sistemas) e menos com a empresa em que trabalham. Do ponto de vista dos profissionais em TI mais especificamente, Chen (2005) demonstra que eles estariam mais sujeitos a pressões normativas, enquanto as organizações em que trabalham estariam mais sujeitas a influências coercitivas e miméticas. ${ }^{7}$

Em TI, padrões profissionais tiveram de se adaptar às exigências do mercado e às mudanças internas nas estruturas organizacionais, tornando capacidades de inovação e flexibilidade os principais critérios para permanência em mercado altamente competitivo (ARTHUR, 1996). No entanto, existiriam muitas dificuldades em definir e medir habilidades e competências em economias em rápida expansão, sendo isso particularmente verdadeiro na área de TI. Além disso, as diferenças entre os padrões de qualificação estabelecidos e oferecidos por instituições (de formação e profissionalização) aumentariam em relação às exigências da indústria de TI. Em casos assim, as empresas contratantes passariam a exigir habilidades adicionais de seus candidatos, especialmente habilidades sociais e de comunicação, bem como de negócios e de marketing (BEN, 2007).

Com base na crescente exigência de novos conhecimentos e habilidades, Coes e Schotanus (2009) discutem as razões pelas quais muitos profissionais de TI buscariam certificações. As razões investigadas seriam autodesenvolvimento, aperfeiçoamento de carreira e obrigação por parte dos empregadores. No entanto, Coes e Schotanus (2009) afirmam que permaneceria certa ambiguidade quanto aos aspectos a favor e contra a certificação, expressa no seguinte questionamento: certificações preencheriam as crescentes lacunas de conhecimento decorrentes da constante evolução da profissionalização e industrialização em TI ou seriam uma estratégia de mercado das organizações certificadoras?

Não obstante, grandes empresas parecem cada vez mais valorizar certificados de qualidade e passam a estabelecer padrões profissionais com base nesses certificados (BEN, 2007). Ao comparar a formação profissional da área de TI com a formação profissional em outras áreas, Donohue e Power (2012) demonstram falta de clareza em TI quanto a educação profissional, acreditação, desenvolvimento de habilidades, certificação, licenciamento, desenvolvimento profissional, código de ética, sociedade profissional e requisitos legais. Nessa comparação destaca-se a ausência de formalidade na área de TI, o que reflete um baixo nível de exigência de entrada, em conjunto com falta de formação de base em TI, sem exigências legais para o licenciamento ou registro do profissional. Observa-se, como consequência, uma prática crescente exercida por muitas organizações: recorrer ao uso de certificações (HUNSINGER, SMITH e WINTER, 2011) orientadas à tarefa, o que lhes permitiria o recrutamento para necessidades específicas (DONOHUE e POWER, 2012), com prejuízos sobre a necessidade de uma formação de base mais ampla na área de TI.

Donohue e Power (2012), corroborando opinião de Collins, Ghey e Mills (1989), preveem que um adequado nível de profissionalização, contemplando educação profissional, acreditação, desenvolvimento de habilidades, certificação, licenciamento, desenvolvimento profissional, código de ética, sociedade profissional e requisitos legais, só viria a acontecer se houvesse um aumento significativo nos casos de litígios decorrentes de falhas em TI.

\footnotetext{
6 Isomorfismo como tendência à homogeneização de estruturas e comportamentos; restrição que força uma unidade em uma população a se assemelhar a outras unidades que enfrentam o mesmo conjunto de condições ambientais (DIMAGGIO e POWELL, 2007).

7 Seriam quatro as forças atuantes sobre processos de mudança institucional: poder (isomorfismo coercitivo), atração (pressões normativas), mimese (processos miméticos) e competição (DIMAGGIO e POWELL, 2007).
} 
Há ainda a participação de profissionais de TI na emergência de novas profissões de cunho interdisciplinar. Podem-se apresentar como exemplos os casos (a) de tecnólogo da aprendizagem, justificado pela necessidade de um novo corpo profissional, voltado especificamente à atuação no campo do ensino a distância (SOYOZ, 2010); (b) da junção entre informática e medicina, que, segundo Hersh (2012) deveria ser objeto de atenção dedicado principalmente aos profissionais de saúde (médicos, enfermeiros) e aos profissionais de TI que atuam conjuntamente; e (c) da diversidade de atuações do profissional de TI - e sua capacidade de ser pervasivo - por meio da imersão em outras áreas e, especificamente, da composição de uma profissão em formação, chamada "informática médica" (ZHANG, 2012).

Adicionalmente, considerando a multiplicidade de aplicações da TI, Shapiro (1994) já questionava sobre a organização do conhecimento e das habilidades na área, ou seja, se deveriam ser repassados conhecimentos específicos de áreas de aplicação aos especialistas em TI, ou se especialistas em conhecimentos específicos deveriam receber conhecimentos de TI.

\section{O Papel dos Profissionais de TI no Processo de Profissionalização: entre o Desejo e a Repulsa}

A retenção de profissionais em TI vem recebendo crescente atenção por parte dos contratantes (LUFTMAN e KEMPAIAH, 2008), uma vez que se tem tal profissional como aquele que está em constante busca por melhores oportunidades na carreira, o que implicaria elevado turnover. No Brasil, acrescenta-se a isso a escassez de mão de obra qualificada na área (SOFTEX, 2012).

De acordo com Bernthal e Wellings (2001), profissionais mais jovens, atuantes especialmente em áreas tecnológicas, oferecem um risco elevado de turnover. Assim, Pipoli e Fuchs (2011) analisam seis práticas comuns na área de retenção: orientação, treinamento, desenvolvimento de carreira, motivação, remuneração e feedback e avaliação. Estas práticas ocorrem em atendimento a uma preocupação típica dos gestores em momentos de crise: a área de TI necessita reter talentos, pois é área que afeta a competitividade e a tomada de decisão.

Informalmente os profissionais de TI tendem a cruzar as fronteiras organizacionais e realizar intercâmbio de informações profissionais em vários ambientes sociais. Tais trocas trariam, muitas vezes, novas ideias e estimulariam o surgimento de inovações na organização, além de permitir a difusão de conhecimentos sobre tecnologias emergentes e adotadas em outras organizações do setor. Esse intercâmbio deveria, então, ser estimulado pela alta gestão como forma de atualização da prática profissional e obtenção de melhores níveis de retenção de seus profissionais de TI (BEN, 2007; CHEN, 2005).

Apesar desses esforços e das demonstrações de aceitação social, profissionais de TI têm enfrentado dificuldades em relação à carreira, à família e ao seu nível de agência - ou seu grau de autonomia em relação à estrutura (social, organizacional, econômica etc.) na qual se inserem -, o que enseja investigações acerca das intenções de mudança de carreira profissional.

Indivíduos altamente comprometidos com suas carreiras demonstram maior dedicação ao desenvolvimento de habilidades e, ao mesmo tempo, apresentam menor grau de intenção de mudança de carreira e/ou emprego, com melhores níveis de desempenho no trabalho que aqueles com menor grau de comprometimento (BLAU, 1989). Entre os antecedentes do comprometimento em TI, a satisfação com a carreira é o mais importante, seguida por autoeficácia, ameaça de obsolescência profissional e investimento na carreira (FU, 2011).

Downey (2010) trata da progressão na carreira para as profissões em TI e investiga a dificuldade que teriam os profissionais de TI para progredir de cargos iniciais técnicos para cargos posteriores de gestão de projetos e equipes. Esses profissionais tenderiam a ser introspectivos e focados na tarefa, enquanto habilidades de comunicação seriam fortemente requeridas para progressão, por exemplo, de programador a chefe da área de TI. Haveria ainda a não preparação, desde a formação profissional básica, para a atuação em gestão. A 
propensão técnica e a busca por desafios tecnológicos são também destacados por Downey (2010) como características dos profissionais de TI, aspectos difíceis de conciliar com uma progressão do tipo hierárquica na carreira.

O contexto da atividade profissional em TI seria causa de conflitos na relação trabalho-família (DINGER, THATCHER e STEPINA, 2010). Requisitos de diversidade de habilidades, aspectos éticos no trabalho, lazer e profissionalismo teriam efeitos sobre o conflito trabalho-família. Sobretudo, Dinger, Thatcher e Stepina (2010) relatam que quando o profissional de TI tem a percepção de segurança no trabalho e está satisfeito com os seus superiores, o conflito trabalho-família tende a diminuir.

Suposições estereotipadas de gênero sobre a perícia na prática do desenvolvimento de software e fatores estruturais relacionados à falta de programas de equilíbrio entre trabalho e vida, bem como a falta de treinamento interno na maioria das empresas de TI, seriam fatores contributivos para um conflito adicional na área: a segregação organizacional relacionada a gênero (BEN, 2007). Para esta autora, as maneiras como se desenvolveram o profissionalismo na criação de software e os significados de gênero na área seriam mutuamente constitutivas.

Considerando, por um lado, o significativo interesse das organizações contratantes em selecionar e manter profissionais de TI em seus quadros e, por outro, as pressões e conflitos a que eles estão sujeitos, seria de se esperar perguntas do tipo "de que forma o profissional de TI lida com essas situações?" ou "quais os meios pelos quais esses profissionais atenuam a tensão inerente à profissão?"

Para Kostera e Postula (2011), interessam os meios adotados pelos profissionais de TI para aumentar seus níveis de agência e, assim, lidar adequadamente com as elevadas expectativas traçadas a seu respeito pela sociedade. Kostera e Postula (2011) relatam que os profissionais de TI procurariam definir sua profissão de forma autônoma, resistindo a categorizações externas, alterando, assim, a agência da construção do seu papel em seu favor. Esses profissionais não desejariam ser jogados em "cestas comuns", para "ser como eles" (p. 89), ou seja, como profissionais cuja denominação de especialização é menos valorizada. A invocação de especializações serviria também como uma ferramenta de ajuste fino no nível intraprofissional, ou seja, serviria de diferenciação em relação a outros profissionais atuantes na área.

Portanto processos organizacionais envolvidos com a área de TI, como aqueles de desenvolvimento e implantação de software customizado, por exemplo, podem ser descritos como processos sociais e políticos, tendo o conflito como elemento incorporado em relações de poder assimétricas, uma vez que (a) são os profissionais de TI que detêm conhecimentos técnicos; (b) criam (e/ou alteram) estruturas organizacionais e procedimentos operacionais que afetam o trabalho dos usuários; (c) estabelecem limites de atuação e de decisão do usuário (embutidos em parâmetros e "regras de negócio" implementados no SI); e (d) exercem influência simbólica sobre os usuários ao inserir no SI elementos culturais associados a valores, ideais e crenças.

A atuação periférica que restaria aos usuários feriria normativas sobre o papel e funções de um comitê de seleção (geralmente formado por diretores e técnicos) em frameworks, como o da melhoria do processo de software brasileiro (MPS.Br) - Guia de Aquisição - e ISO 12207, que tratam do processo de aquisição de software e serviços correlatos (SOFTEX, 2011).

\section{Discussão}

Os pontos de controvérsia, presentes na literatura sobre profissionalização em TI, quando confrontados com as perspectivas propostas por Abbott (1988) e Freidson (1984), especificamente em relação aos aspectos jurisdicionais e interacionistas da geração, manutenção e aplicação do conhecimento (formal, abstrato e acadêmico), ajudam a fornecer indicações a respeito de um campo de atuação profissional que se mostra difuso em vários aspectos. 
O primeiro é que tal campo não demonstra "espírito" de corpo. Ou seja, nele não ocorrem ou se defendem propostas de profissão e especialidades com base em uma identidade profissional. Segundo, a adaptação à mudança deu-se, de tal forma, que tornou-o volúvel na própria definição e na imagem que se esforça para imprimir na sociedade. Terceiro, apesar de possuir o poder de representar forte papel social - evidente na dependência que a sociedade tem, hoje, do adequado funcionamento das TICs -, não consegue convertê-lo em capital social que financie sua profissionalização, limitando-se ao capital econômico capaz de auferir individualmente - perde-se a oportunidade momentânea única de aproveitamento desse valor social. E, quarto ponto, confluência (e talvez causa) de todos os demais, capitulação às determinações dos provedores de tecnologia e dos contratantes nos aspectos fundamentais da constituição da sua profissão: reprodução, regulação e autonomia.

Observando-se essas questões em detalhe e, ao mesmo tempo, em conjunto e em confronto com a literatura, obtém-se um quadro relativamente complexo da situação. A questão central, dado o seu peso na existência (e sobrevivência) das profissões e especialidades de TI, parece ser a legitimação, e legitimação é conferida pela sociedade (clientes/usuários, Estado, profissionais externos à área e profissionais internos) (RODRIGUES, 2002; RODRIGUEZ e GUILLEN, 1992). Sendo esse pressuposto verdadeiro, não se pode afirmar que haja legitimação para as profissões em TI, uma vez que o Estado reluta em conceder os benefícios do reconhecimento profissional (COBURN, 1994; ILAVARASAN e MALISH, 2008), parte dos próprios profissionais relutam em ter a profissão regulamentada (PETIÇÃO PÚBLICA, n.d.) e outras profissões reclamam ascendência sobre a área (HERSH, 2012). Esforços comuns de busca por legitimação, como o argumento do aumento da "produtividade" (CASTELLS, 1999; FURTMUELLER WILDEROM e RAO, 2011; PRICE, 2006), que justificaria a relevância da profissão para a sociedade, não parecem ter a repercussão desejada, afetando apenas a parcela da sociedade diretamente interessada, ou seja, contratantes e, eventualmente, usuários diretos.

Se os profissionais de TI estão mesmo preocupados, primordialmente, em justificar a necessidade de sua atuação com os contratantes, e são os contratantes que selecionam e contratam os profissionais em virtude de tecnologia específica (BEN, 2007; COES e SCHOTANUS, 2009), viria daí a segunda questão a discutir. Isto é, seria possível inferir a influência do fornecedor/provedor de tecnologia sobre o profissional de TI, ao estabelecer o conjunto de conhecimentos e práticas requeridos para a sua atuação, e sobre a constituição da profissão, ao delimitar as capacidades oferecidas pela tecnologia e o seu espectro de aplicação? Assim, de maneira diversa à de profissões clássicas (BARBOSA, 2003), no sentido de sua autonomia de saberes e aplicações, as profissões em TI surgiriam vinculadas a uma determinada indústria.

O ponto central dessa discussão é, portanto, o vínculo entre a atuação profissional em TI, os saberes detidos/requeridos por esse (e desse) profissional e as tecnologias de aplicação desses saberes que, por definição, são elaboradas e dispostas por uma indústria específica. Mesmo o defensor mais ardoroso do conceito de "software livre" haveria de concordar com esse vínculo, ou em outros termos, com essa dependência. Então, tem-se que a influência da indústria no estabelecimento das tecnologias teria também sua contribuição percebida na desqualificação (ORLIKOWSKI e BAROUDI, 1988). O profissional de TI sofreria, assim, a dupla pressão: (a) manter-se atualizado e produtivo nas novas tecnologias e (b) adaptar-se à aquisição constante de técnicas e habilidades, mormente relacionadas à administração e ao gerenciamento de recursos (BEN, 2007; COES e SCHOTANUS, 2009).

Não seria o ideário do "software livre" também, para além da questão econômica, uma manifestação da busca por se libertar dessa dominação da indústria? A democracia representativa, como o modelo político da sociedade da informação (BARDINI, 2000), não teria também sua relevância ao influenciar o pensamento do profissional de TI, principalmente aquele imbuído do ideário do "software livre"?

Tais questionamentos têm justificativa: como o ideário do "software livre" está, ele mesmo, sujeito às regras da "ideologia modernista", nos termos de Bardini (2000), ou seja, determinado pela tecnologia (indústria de TI) e pelos contratantes, restaria ao profissional de TI buscar espaços de arbitrariedade, isto é, lacunas não reguladas ou normatizadas no âmbito da sua atuação profissional, nas quais seja possível arbitrar o seu papel. 
Seria nesse sentido que Bittner (2004) e Markus e Bjorn-Andersen (1987) tratariam o exercício do poder por parte dos profissionais de TI sobre os usuários e processos organizacionais. Ainda assim, seria possível questionar se as formas de exercício do poder não estariam atreladas, alternativamente, a estratégias de supressão do conflito. A tecnologia (um SI, por exemplo) seria apresentada aos usuários como taken for granted e legitimada (HARDY e LEIBA-O'SULLIVAN, 1998) pela direção e pelo corpo técnico de TI. No entanto, de que forma esse "poder" atribuído pela direção aos profissionais de TI teria seu preço cobrado em seguida? Estudos empíricos (DE MOURA JR. e BELLINI, 2012) demonstram que a inserção de tecnologias no âmbito organizacional não deveria prescindir da participação ativa do usuário final (ou usuário-chave), sob significativo risco de insucesso. Assim, poder-se-ia argumentar que esse poder deveria ser tratado como ilusório, já que o seu custo seria a forçosa obtenção de sucesso do projeto, mesmo à revelia do usuário final, o que implicaria aumento do nível de exigência sobre o profissional de TI.

Lacunas regulatórias e/ou normativas também dariam margem à autorregulação. Nomear os próprios cargos e postos de trabalho (KOSTERA e POSTULA, 2011) seria, assim, uma forma de arbitrariedade, mas, principalmente, de diferenciação em relação a profissionais considerados de menor qualidade técnica. Essa última inferência parece ser particularmente evidente quando se constata a facilidade de exercício profissional em TI, haja vista a inexistência de normas de conformidade para licenciamento profissional (DONOHUE e POWER, 2012). Já que não há regulamentação que ofereça segurança aos profissionais de TI, a criação dos próprios mecanismos de proteção parece ser opção legítima. O que se poderia colocar é: até que ponto essa autorregulação não seria prejudicial à sociedade?

Uma terceira questão que emerge da controvérsia presente na literatura sobre profissionalização em TI refere-se à normatização da profissão. Especificamente em relação à multiplicidade de aplicações da TI, resgata-se questionamento de Shapiro (1994) sobre a organização do conhecimento e das habilidades, ou seja, se deveriam ser repassados conhecimentos específicos de áreas de aplicação aos especialistas em TI, ou se especialistas em outros domínios específicos deveriam receber conhecimentos de TI. Independente da resposta, o que se pode acrescentar é que se observa, cada vez mais comumente, profissionais de TI sendo convidados a assumir postos de direção em áreas específicas - não de TI - devido ao domínio de conhecimentos adquiridos naquela área específica; em etapas de implantação de SI, por exemplo. Esse aspecto afetaria, inclusive, questões de progressão na carreira (LUFTMAN e KEMPAIAH, 2008; RODRIGUES, 2002) e contribuiria para a escassez de profissionais experientes de TI que prossigam na carreira até o fim.

A despeito da indefinição de questões normativas sobre as profissões em TI, observa-se um fenômeno que pressupõe a não necessidade dessa discussão (ou assume que esteja resolvida): a participação de profissionais de TI na emergência de (outras) novas profissões de cunho interdisciplinar (HERSH, 2012; SOYOZ, 2010; ZHANG, 2012), que adiciona complexidade significativa à discussão. Como uma ocupação (e suas especialidades) que ainda está em processo de profissionalização (ABBOTT, 1988) poderia estar afetando a composição de novas ocupações, também em processo de profissionalização, como os informáticos médicos (HERSH, 2012) ou os tecnólogos da aprendizagem (SOYOZ, 2010)?

A necessidade imperativa de se conhecer o profissional que atua na área da saúde (HERSH, 2012), seja profissional de TI ou de outra área, evidenciaria um conjunto de preocupações (não exaustivo aqui) que tende a dominar a discussão sobre a profissionalização em TI: (a) quem são os profissionais que desenvolvem e implantam tecnologias da informação? (b) quais habilidades e competências devem ser esperadas desses profissionais? (c) como garantir que esses profissionais tenham obtido licenciamento para atuar profissionalmente? (d) especificamente em áreas críticas, como saúde ou tráfego aéreo, por exemplo, deveriam os profissionais dessas áreas se especializar em TI ou deveriam os profissionais de TI buscar conhecimentos especializados em cada área de atuação?

O conjunto das discussões apresentadas oferece subsídios para elaboração de proposições específicas de pesquisa de natureza crítica: (1) decorrente da ideia utópica das escolhas democráticas (BARDINI, 2000), teria a democracia representativa, como o modelo político da sociedade da informação, influência sobre o 
pensamento do profissional de TI? Considerando que são os contratantes que selecionam e contratam os profissionais em função de tecnologia específica (BEN, 2007; COES e SCHOTANUS, 2009), (1.a) existiria, de fato, determinação da indústria de TI sobre a ação profissional em TI e (1.b) o ideário do "software livre" seria representativo de esforço de libertação de uma eventual dominação da indústria? Ainda nesse sentido crítico e considerando as questões de poder (BITTNER, 2004; MARKUS e BJORN-ANDERSEN, 1987), (1.c) seriam as relações de poder entre contratantes, profissionais e usuários de TI assimétricas e refletiriam outros aspectos além de dominação, como reação e ilusão?

O conjunto das discussões apresentadas também oferece subsídios para elaboração de proposições específicas de pesquisa de natureza ocupacional: (2) decorrente da arbitrariedade de nomeação dos próprios cargos e postos de trabalho (KOSTERA e POSTULA, 2011), os profissionais de TI praticariam autorregulação da profissão (e especialidades) e o fariam por meio do domínio do conhecimento? (2.a) características pessoais dos profissionais de TI, como traços de personalidade, visão de mundo e cultura (BARDINI, 2000; BEN, 2007), afetariam (dificultariam) o estabelecimento de regulamentação da profissão? Haja vista a inexistência de normas de conformidade para licenciamento (DONOHUE e POWER, 2012) profissional, (2.b) ocorrências de litígio seriam iminentes e, apesar de indesejáveis, influenciariam positivamente a exigência social de licenciamento para exercício da profissão?

O conjunto das discussões apresentadas oferece, por fim, subsídios para elaboração de proposições específicas de pesquisa quanto à natureza transitória e pervasiva das profissões em TI: (3) considerando-se a existência de movimento de participação dos profissionais de TI em novas profissões (HERSH, 2012; SOYOZ, 2010), esse movimento poderia ser indicativo de que o profissional de TI "puro" seria um fenômeno transitório? Como alternativa a esse movimento de "diluição" da profíssão de TI, (3.a) o conjunto de habilidades e competências esperadas dos profissionais de TI (GRAJEK, 2011; LASWELL, SIMMEL e BEHRENS, 1999; SEGRE e RAPKIEWICZ, 2003) tenderia a crescer e se diversificar, avançando por outros domínios do saber?

\section{Conclusão}

Com o intuito de discutir o processo, em curso, de construção das profissões em TI e o papel desempenhado pelos profissionais da área nesse processo, foram apresentados neste ensaio a literatura oriunda da sociologia sobre as profissões; as discussões correntes sobre a profissionalização específica em TI; as discussões correntes sobre o papel que tem sido desempenhado pelos profissionais de TI no processo de profissionalização; e, por fim, sugeriram-se importantes insights, posicionamentos e questionamentos sobre o tema.

Os posicionamentos teóricos de Abbott (1988) e Freidson (1984), de cunho jurisdicional e interacionista respectivamente, propiciaram o enquadramento da análise da profissionalização e da atuação profissional em TI - com base na posse e emprego do conhecimento (formal, abstrato, acadêmico) - como o principal instrumento estruturador dos grupos ocupacionais. E ofereceram também uma perspectiva específica na busca pelas respostas para as seguintes questões: quem são os profissionais de TI? Como se dá a sua formação? Quais são os instrumentos de regulamentação da sua atuação?

Nessa busca, identificaram-se pontos de controvérsia presentes na literatura sobre profissionalização em TI. A saber, (a) alguns autores entendem que a atuação profissional em TI ainda seria caracterizada como ocupação, enquanto outros perceberiam um processo em curso de profissionalização; (b) os modelos adotados para análise da profissão em TI seriam conflitantes, ora abordando a profissionalização em TI como um sistema binário, ora como uma miríade de dimensões de análise; (c) alguns profissionais em TI destacam o papel social e econômico, simultaneamente, da profissão, enquanto outros se concentram nos aspectos meramente econômicos; e (d) a influência de aspectos regulatórios e, portanto, externos, seria maior que aspectos normativos (sob domínio da profissão). 
Identificaram-se conflitos nos níveis intra e extraprofissionais, a saber, aprendizado e adaptação constantes versus desqualificação; desequilíbrios na relação trabalho-família; gênero versus atribuições profissionais; conhecimento profissional codificado na estrutura organizacional versus estruturação na expertise; aumento dos níveis de agência versus elevadas expectativas traçadas pela sociedade; e exercício de poder versus poder ilusório.

Por fim, a discussão das referências teóricas adotadas e das controvérsias e conflitos identificados suscitou a elaboração de alguns questionamentos, cuja investigação transcenderia o escopo de um ensaio, como este, de perspectiva panorâmica. Esses questionamentos evocados versam sobre temáticas relativas ao ideário do "software livre", à determinação da indústria de TI sobre a ação profissional em TI, às relações de poder, à autorregulação da profissão (e especialidades), à participação dos profissionais de TI em novas profissões, às características pessoais dos profissionais (traços de personalidade, visão de mundo, cultura), às habilidades e competências esperadas desses profissionais, ao licenciamento para exercício da profissão, ao domínio do conhecimento e a aspectos de litígio. É de se esperar que cada um desses questionamentos venha a originar investigação e discussão em profundidade.

\section{Referências}

ABBOTT, A. The system of professions. Chicago: University of Chicago Press, 1988.

ARTHUR, W. B. Increasing returns and the new world of business. Harvard Business Review, v. 74, n. 4, p. 100-109, 1996.

BARBOSA, M. L. O. Ensaio bibliográfico: as profissões no Brasil e sua sociologia. DADOS - Revista de Ciências Sociais, v. 46, n. 3, p. 593-607, 2003.

BARDINI, T. Les promesses de la révolution virtuelle: Genèse de l'informatique personnelle, 1968-1973. Sociologie et Société, v. 32, n. 2, p. 57-72, 2000.

BARNES, B. H.; GOTTERER, M. H. Attributes of computer professionals. In: 13th ANNUAL SIGCPR CONFERENCE, ACM, 1975. Proceedings... 31-39 p.

BEN, E. R. Defining expertise in software development while doing gender. Gender, Word and Organization, v. 14, n. 4, p. 312-332, 2007.

BENBASAT, I.; ZMUD, R. W. The identity crisis within the IS discipline: defining and communicating the discipline's core properties. Management Information Systems Quarterly, v. 27, n. 2, p. 183-194, 2003.

BERNTHAL, P. R.; WELLINS, R. Retaining talent: a benchmarking study. Bridgeville, PA: Development Dimensions International, 2001.

BITTNER, P. On professional informatical action. International Journal of Information Ethics, v. 2, p. 1-8, 2004.

BLAU, G. J. Testing the generalizability of a career commitment measure and its impact on employee turnover. Journal of Vocational Behavior, v. 35, n. 1, p. 88-103, 1989.

BRINT, S. Profesiones y mercado. REIS - Revista Española de Investigaciones Sociológicas, n. 59, p. 161-203, 1992.

BUREAU, S.; SUQUET, G. B. A professionalization framework to understand the structuring of work. European Management Journal, v. 27, n. 6, p. 467-475, 2009.

CARR-SAUnders, A. M.; WILSON, P. A. The Professions. Oxford: Clarendon Press, 1933.

CASTELLS, M. A sociedade em rede. São Paulo: Paz e Terra, 1999. 
CHEN, W. Isomorphism and mobile commerce strategy. In: 5th INTERNATIONAL CONFERENCE ON ELECTRONIC BUSINESS, Hong Kong, Dec. 5-9, 2005. Proceedings... 599-607 p.

COBURN, D. Professionalization and proletarianization: medicine, nursing and chiropractic in historical perspective. Labour/Le Travail, v. 34, p. 139-162, Fall/Automne, 1994.

COES, G.; SCHOTANUS, K. Certification: Who dares? IT Professional, p. 50-52, May/June 2009.

COLLINS, S.; GHEY, J.; MILLS, G. The professional engineer in society: a textbook for engineering students. London: Jessica Kingsley Publishers, 1989.

DE MOURA JR., P. J.; BELLINI, C. G. P. Gestão de equipes-cliente na implantação de sistemas ERP: uma grade de repertórios estruturais, cognitivos e comportamentais no Nordeste brasileiro. In: XXXVI ENCONTRO ANUAL DA ANPAD, EnANPAD 2012, Rio de Janeiro, 2012. Anais... Rio de Janeiro: ANPAD.

DENNING, P. J. The profession of IT: Who are we? Communications of the ACM, v. 44, n. 2, p. 15-19, 2001.

DIMAGGIO, P. J.; POWELL, W. W. Jaula de ferro revisitada: isomorfismo institucional e racionalidade coletiva nos campos organizacionais. In: CALDAS, M. P.; BERTERO, C. O. (Orgs.). Teoria das Organizações. São Paulo: Atlas, 2007. p. 117-142.

DINGER, M.; THATCHER, J. B.; STEPINA, L. P. A study of work-family conflict among IT professionals: job characteristics, individual values, and management practices. Journal of Organizational Computing and Electronic Commerce, v. 20, n. 1, p. 91-121, 2010.

DONOHUE, P.; POWER, N. Legacy job titles in IT: the search for clarity. In: 50TH ANNUAL CONFERENCE ON COMPUTERS AND PEOPLE RESEARCH, SIGMIS-CPR'12, May 31-June 2, 2012, Milwaukee, Wisconsin, USA. Proceedings...

DOWNEY, J. Careers in software: is there life after programming? In: 49TH ANNUAL CONFERENCE ON COMPUTERS AND PEOPLE RESEARCH, SIGMIS-CPR'10, May 20-22, 2010, Vancouver, Canada. Proceedings...

EMMERICH, H. T. Bioethics critically reconsidered: having second thoughts. Philosophy in Review, v. 32, n. 3, p. 170-173, 2012.

FREEMAN, P.; ASPRAY, W. The supply of information technology workers in the United States. Washington: Computing Research Association, 1999.

FREIDSON, E. The changing nature of professional control. Annual Review of Sociology, v. 10, p. 1-20, 1984.

Professional Powers: a study of the institutionalization of the formal knowledge. Chicago: The University of Chicago Press, 1986.

FU, J. R. Understanding career commitment of IT professionals: perspectives of push-pull-mooring framework and investment model. International Journal of Information Management, v. 31, n. 3, p. 279-293, 2011.

FURTMUELLER, E.; WILDEROM, C.; RAO, P. Young IT professionals' preferred recruiting modes in the contemporary economy. European Journal of Management, v. 11, n. 1, p. 1-18, 2011.

GRAJEK, S. Research and data services for higher education information technology: past, present and future. Educause Review, Nov./Dec., p. 46-60, 2011.

HARDY, C.; LEIBA-O'SULLIVAN, S. The power behind empowerment: implications for research and practice. Human Relations, v. 51, n. 4, p. 451-483, 1998.

HAUG, M. R. Deprofessionalization: an alternative hypothesis for the future. Sociological Review Monograph, v. 20 , p. 195-211, 1973. 
HERSH, W. Who are the informaticians? What we know and should know. Journal of the American Medical Informatics Association, v. 13, n. 2, p. 166-170, 2012.

HU, Q.; HART, P.; COOKE, D. The role of external influences on organizational information security practices: an institutional perspective. In: 39TH ANNUAL HAWAII INTERNATIONAL CONFERENCE ON SYSTEM SCIENCES, HICSS'06, 2006. Proceedings...

HUGHES, E. C. Men and Their Work. Glencoe, Ill.: Free Press, 1958.

HUNSINGER, D. S.; SMITH, M. A.; WINTER, S. J. A framework of the use of certifications by hiring personnel in IT hiring decisions. The DATA BASE for Advances in Information Systems, v. 42, n. 1, p. 9-28, 2011.

ILAVARASAN, P. V.; MALISH, C. M. Computing professionals in e-governance: policy implications. In: 2ND INTERNATIONAL CONFERENCE ON THEORY AND PRACTICE OF ELECTRONIC GOVERNANCE, ICEGOV'08, Cairo, Egypt, ACM New York, NY, USA, 2008. Proceedings... 239-244 p.

KALLINIKOS, J.; AALTONEN, A.; MARTON, A. The ambivalent ontology of digital artifacts. Management Information Systems Quarterly, v. 37, n. 2, p. 357-370, 2013.

KOSTERA, M.; POSTULA, A. Holding up the Aegis: on the construction of social roles by Polish IT-professionals and the change in agency. Journal for Critical Organization Inquiry, v. 9, n. 1/2, p. 83-92, 2011.

LASWELL, B. S.; SIMMEL, D.; BEHRENS, S. G. Information assurance curriculum and certification: state of the practice. Pittsburgh, PA: Software Engineering Institute, Carnegie Mellon, 1999. 1-20 p.

LEUNG, L. Effects of ICT connectedness, permeability, flexibility, and negative spillovers on burnout and job and family satisfaction. Human Technology, v. 7, n. 3, p. 250-267, 2011.

LUFTMAN, J.; KEMPAIAH, R. Key issues for IT executives 2007. MIS Quartely Executive, v. 7, n. 2, p. 99-12, 2008.

MARKUS, M. L.; BJØRN-ANDERSEN, N. Power over users: Its exercise by systems professionals. Communications of the ACM, v. 30, p. 498-504, 1987.

MEYER, J. W.; BOLI, J.; THOMAS, G. M. Ontology and rationalization in the Western cultural account. In: SCOTT, W. R.; MEYER, J. (Orgs.). Institutional environments and organizations: structural complexity and individualism. Thousand Oaks, CA: Sage, 1994. 9-27 p.

MOTA, F. P. B.; DE MOURA JR. P. J.; BELliNI, C. G. P. Penso, logo existo? Reflexões paradigmáticas em tecnologia da informação. In: XXXVII ENCONTRO ANUAL DA ANPAD, EnANPAD, 2013, Rio de Janeiro. Anais... Rio de Janeiro: ANPAD.

NEVO, S.; NEVO, D.; EIN-DOR, P. Thirty Years of IS Research: Core Artifacts and Academic Identity. Communications of the Association for Information Systems, v. 25, p. 221-242, 2009.

ORLIKOWSKI, W. J.; BAROUDI, J. J. The information systems profession: myth or reality? Information Technology and People, v. 4, n. 1, p. 13-30, 1988.

PARSONS, T. Professions. In: SILLS, V. (Ed.). International Encyclopaedia of Social Sciences. v. XII. London: The Macmillan Company \& The Free Press, 1968.

PETIÇÃO PÚBLICA. Abaixo-assinado Carta contra PL de regulamentação da profissão de Analista de Sistemas. n.d., Disponível em: http://www.peticaopublica.com.br/?pi=P2012N30508. Acesso em: 13 de fev. 2013

PIPOLI, G.; FUCHS, R. M. Retaining IT professionals. In: LUFTMAN, J. Managing IT human resources: considerations for organizations and personnel. Hershey, PA: Business Science Reference, 2011.

PRICE, K. The changing landscape. ITNow, The British Computer Society, p. 14-15, 2006. 
RODRIGUES, M. L. Sociologia das profissões. 2. ed. Oeiras: Celta, 2002.

RODRIGUEZ, J. A.; GUILLEN, M. F. Organizaciones y profesiones en la sociedad contemporánea. REIS - Revista Española de Investigaciones Sociológicas, v. 59, p. 9-18, 1992.

SANTOS, A. F. P. R. Principais abordagens sociológicas para análise das profissões. Revista Brasileira de Informação Bibliográfica em Ciências Sociais, São Paulo, v. 71, n. 1, p. 21-43, 2011.

SCOTT, W. R. Institutions and organizations. Thousands Oaks: Sage Publications, 1995.

SEGRE, L. M.; RAPKIEWICZ, C. E. Mercado de trabajo y formación de recursos humanos en tecnologia de la información en Brasil. ¿Encuentro o desencuentro? In: LABARCA, G. (Coord.). Reformas económicas y formación. Montevideo: CINTERFOR/GTZ/CEPAL, 2003.

SHAPIRO, S. Boundaries and quandaries: establishing a professional context for IT. Information Technology and People, v. 7, n. 1, p. 48-68, 1994.

SOFTEX. Software e serviços de TI: a indústria brasileira em perspectiva. Campinas: SOFTEX, 2012.

SOYOZ, S. Identifying e-learning technologists: Key roles, activities and values of an emerging group. eLearn Magazine: education and technology in perspective, ACM, v. 10, 2010.

VENUTO, A. A astrologia como campo profissional em formação. Dados, Rio de Janeiro, v. 42, n. 4, 1999.

WILENSKY, H. L. The Professionalization of Everyone? American Journal of Sociology, v. 70, n. 2, p. 137-158, 1964.

ZHANG, L. Study on domestic medical informatics talent cultivation and development countermeasure. In: INTERNATIONAL SYMPOSIUM ON INFORMATION TECHNOLOGY IN MEDICINE AND EDUCATION, ITME, Aug. 3-5, p. 91-93, 2012. Proceedings... 